\title{
CSL grain boundary distribution in alumina and zirconia ceramics
}

\author{
Pierre Vonlanthen *, Bernard Grobety \\ Department of Geosciences, University of Fribourg, Chemin du Musée 6, CH-1700 Fribourg, Switzerland
}

\begin{abstract}
The distributions of general and coincidence site lattice (CSL) grain boundaries (GBs) in texture-free alumina and zirconia ceramics sintered at two different temperatures were investigated based on electron backscatter diffraction (EBSD) measurements. Results were compared with the distributions obtained from random 2D spatial models and with calculated random distributions reported in the literature. All alumina samples independent on sintering temperature show the same characteristic deviations of the measured general GB distributions from the random model. No such features can be seen in zirconia. The total fractions of CSL GBs in alumina and zirconia samples are clearly larger, for both sintering temperatures, than those observed in the random simulations. A general GB prominence factor, similar to the twin prominence factor for fcc metals, was defined to simplify the representation of the CSL GB content in zirconia. The observed deviations from the random model show no dependence on sintering temperature nor on lattice geometry. In alumina, however, the change in the CSL GB character distribution with sintering temperature seems to be crystallographically controlled, i.e. directly dependent on the orientation of the CSL misorientation axis.
\end{abstract}

Keywords: B. Grain boundaries; D. $\mathrm{Al}_{2} \mathrm{O}_{3}$; D. $\mathrm{ZrO}_{2}$; Electron backscatter diffraction (EBSD)

\section{Introduction}

Grain boundaries (GBs) have a significant influence on important sintering processes such as densification [1], grain growth [2], creep [3-5], segregation [6,7], diffusion [8], as well as on electrical [9], mechanical [10], superconducting [11-13] and optical [14] properties. The importance of GBs on the overall properties of ceramics depends on several factors, including the density of GBs in the material, the chemical composition of the interface and the crystallographic texture, i.e. the GB plane orientations and grain misorientation. A special role is played by the coincidence site lattice (CSL) GBs $[15,16]$. CSL GBs are characterized by the multiplicity index $\Sigma$, which is defined as the ratio between the crystal lattice site density of the two grains meeting at the GB and the density of sites that coincide when superimposing both crystal lattices. For simple structures, it is generally admitted that GBs with low $\Sigma$ values have a tendency for low interfacial energy and special properties. Thus, the study of the proportion of special GBs and of the distribution of grain

\footnotetext{
* Corresponding author. Tel.: +41 2630089 33; fax: +41263009742. E-mail address: pierre.vonlanthen@unifr.ch (P. Vonlanthen).
}

misorientation inferred from the CSL model can be considered as a prerequisite to understand the relationship between microstructure and the properties of ceramics, from which further detailed investigations are carried out (e.g. Refs. [5,6]).

In recent years, a scanning electron microscope (SEM)based technique known as electron backscatter diffraction (EBSD) has been used in a few specific studies dealing with GBs in ceramic materials, e.g. to investigate the relationship between grain misorientation and crack propagation [17], abnormal grain growth [18], and doping [7,19] in alumina, or to determine the lattice preferred orientation (LPO) in zirconia [20] and zirconia-based ceramic composites [21]. The distribution of grain misorientation and CSL GBs in similar materials were investigated by other authors (e.g. Ref. [5]) through time consuming and fastidious TEM analyses of individual GBs. In general, the authors compared CSL distributions of samples with different compositions or process histories, but not with modeled distributions. In this paper, the grain misorientation and CSL GB distributions for texture-free alumina and zirconia ceramics sintered at two different temperatures are presented based on large GB sampling, and the results are compared with the values obtained from simulated random 2D spatial models. 


\section{Experimental methods}

\subsection{Ceramic processing and sample preparation}

Two ceramic suspensions, containing respectively $80 \%$ Mg-doped alumina (Alcoa CT3000 $\mathrm{SG}^{\mathrm{R}}$ ) and 80\% zirconia (Tosoh TZ-8YS ${ }^{\circledR}, 8 \mathrm{~mol} \%$ yttrium-stabilized) (Fig. 1) in distilled water were ball milled for $24 \mathrm{~h}$ in polyethylene jars. An organic surfactant and a molecular binder were added to the suspensions to prevent coagulation and to ensure compact strength after shaping. The powders were dried and granulated using a Büchi ${ }^{\circledR}$ B-190 mini spray dryer and subsequently pressed uniaxially into disks, $15 \mathrm{~mm}$ in diameter and approximately $10 \mathrm{~mm}$ thick, at 75-200 $\mathrm{MPa}$. Isostatic pressing at $200 \mathrm{MPa}$ was then performed to remove the internal residual strain induced by die pressing. Four alumina and four zirconia compacts were prepared. Two of each kind were sintered at $1550{ }^{\circ} \mathrm{C}$ for $4 \mathrm{~h}$ at a basic heating rate of $300{ }^{\circ} \mathrm{C} / \mathrm{h}$. A lower rate of $100{ }^{\circ} \mathrm{C} / \mathrm{h}$ was chosen below $300{ }^{\circ} \mathrm{C}$ to induce a complete burnout of the binder, as well as between 800 and $1150{ }^{\circ} \mathrm{C}$ to improve the densification of the compacts. The remaining two alumina and two zirconia green bodies were fired at $1700{ }^{\circ} \mathrm{C}$ following the same heating profile. Bulk density measurements were performed using Archimedes' principle. They revealed values ranging from 97.0 to $98.2 \%$ of their respective theoretical density (Table 1).
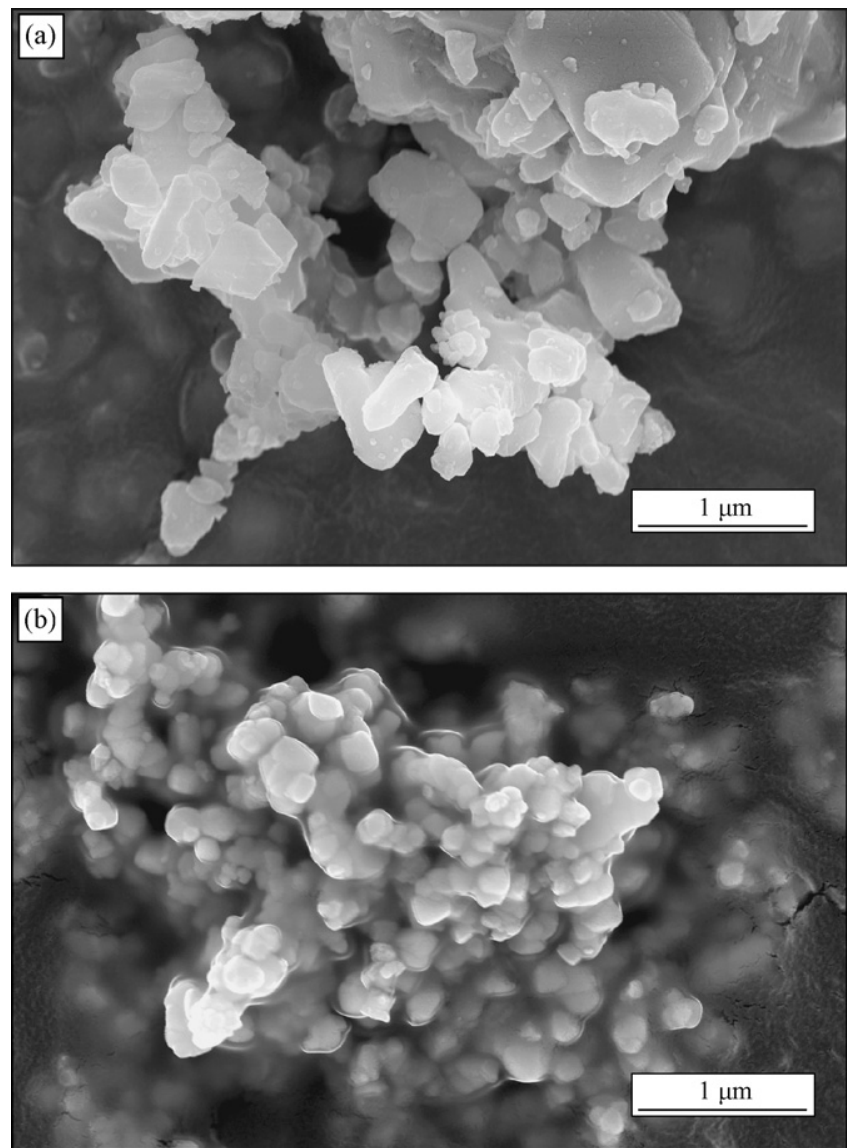

Fig. 1. SEM secondary electron images of the as-received powders. The particles are platelet-shaped in alumina (a) and more regular in zirconia (b).
For each sample, one of the two flat surfaces of the disk was prepared for EBSD, first through grinding and polishing with diamond paste, then through lapping for $6 \mathrm{~h}$ using a colloidal silica suspension (grain size $25 \mathrm{~nm}$ ). To avoid specimen charging, the sample surface was coated with a $4 \mathrm{~nm}$ carbon layer and connected with silver paint to the sample holder.

\subsection{Electron backscatter diffraction (EBSD)}

The EBSD technique is based on automatic analysis of Kikuchi-type diffraction patterns generated by backscattered electrons (see Ref. [22] for a complete review). For each point of analysis, the crystallographic orientation is determined after indexing of the corresponding diffraction pattern. The electron microscopy image simulation (EMS) software developed by Stadelmann [23] was used to generate the reflectors included in the crystallographic material files needed for indexing. All EBSD data were collected with a Philips ${ }^{\circledR}$ FEI XL30 SFEG Sirion SEM equipped with the $\operatorname{EDAX}^{\circledR}$ (TSL) OIM 3.5 software package. The best results were obtained with an acceleration voltage of 20 or $25 \mathrm{kV}$ for a probe current of $20 \mathrm{nA}$.

For each sample, four scans were performed in beam scan mode. The data of the first scans (numbered 1 in Table 1) were used to generate the pole figures of the samples. To avoid redundant point measurements from the same grains and improve grain statistics, large step sizes were selected, i.e. $5 \mu \mathrm{m} / \mathrm{step}$ for an area of $500 \mu \mathrm{m} \times 500 \mu \mathrm{m}$ and $15 \mu \mathrm{m} / \mathrm{step}$ for an area of $1500 \mu \mathrm{m} \times 1500 \mu \mathrm{m}$ were chosen for the fine $\left(1550{ }^{\circ} \mathrm{C}\right)$ and coarse $\left(1700{ }^{\circ} \mathrm{C}\right)$ grained samples, respectively. The data of the three other scans (2, 3 and 4) were used to map the microstructure and highlight the GBs (Fig. 2). In order to improve the pixel resolution of the maps, small step size/areas of $0.4 \mu \mathrm{m} / 50 \mu \mathrm{m} \times 50 \mu \mathrm{m}$ and $0.8 \mu \mathrm{m} / 100 \mu \mathrm{m} \times 100 \mu \mathrm{m}$ were preferred for the fine and coarse grained samples, respectively.

To estimate the strength of the LPO, the texture index $J$ was calculated as the mean square value of the orientation distribution function [24]. A purely random LPO gives a $J$ of 1, whereas for a single crystal, the texture index tends to infinity (in reality to about 24 due to the truncation to 22 in spherical harmonics calculations and the Gaussian half-width of $15^{\circ}$ used).

The GBs satisfying the CSL model for $\Sigma$ values up to 49 were automatically detected for the cubic material (zirconia), using the list integrated in the software (see also Ref. [25]). For alumina, the constrained CSL model [26] adapted for hexagonal lattices by Grimmer [27] was used, considering $\Sigma$ values up to 28 (Table 2). In this latter case coincidence is defined for specific $c / a$ ratios; only CSLs with misorientation axes parallel to [0 0001$]$ are independent of the lattice parameters. Following the recommendations of Grimmer [27], all common (unspecific) and specific coincidence misorientations for $c / a$ ratios ranging from 2.699 to 2.763 were included, assuming that small deviations from the exact $c / a$ value for the studied alumina (2.726 in the present samples, calculated using the Rietveld refinement method) could be accommodated by dislocations. For both 
Table 1

Bulk properties and EBSD data for the eight ceramic samples

\begin{tabular}{|c|c|c|c|c|c|c|c|c|c|}
\hline Sample & $\begin{array}{l}\text { Firing } \\
\text { temperature }\left({ }^{\circ} \mathrm{C}\right)\end{array}$ & $\begin{array}{l}\text { Bulk/theoretical } \\
\text { density }^{\text {a }}(\%)\end{array}$ & Scan & $\begin{array}{l}\text { Step size } \\
(\mu \mathrm{m})\end{array}$ & $\begin{array}{l}\text { Area } \\
\left(\mu \mathrm{m}^{2}\right)\end{array}$ & $\begin{array}{l}\text { Measurements } \\
\text { with } \mathrm{CI} \geq 0.2(\%)\end{array}$ & $\begin{array}{l}\text { Average } \\
\mathrm{CI}^{\mathrm{b}}\end{array}$ & $\begin{array}{l}\text { Number } \\
\text { of grains }\end{array}$ & $\begin{array}{l}\text { Average grain } \\
\text { diameter }^{\mathrm{c}}(\mu \mathrm{m})\end{array}$ \\
\hline A1 & 1550 & 98.0 & $\begin{array}{l}1 \\
2 \\
3 \\
4\end{array}$ & $\begin{array}{l}5 \\
0.4 \\
0.4 \\
0.4\end{array}$ & $\begin{array}{r}500 \times 500 \\
50 \times 50 \\
50 \times 50 \\
50 \times 50\end{array}$ & $\begin{array}{l}44.6 \\
65.1 \\
67.3 \\
74.5\end{array}$ & $\begin{array}{l}0.25(0.48) \\
0.37(0.53) \\
0.38(0.53) \\
0.43(0.56)\end{array}$ & $\begin{array}{r}5195 \\
556 \\
549 \\
730\end{array}$ & 2.1 \\
\hline A 2 & 1550 & 98.0 & $\begin{array}{l}1 \\
2 \\
3 \\
4\end{array}$ & $\begin{array}{l}5 \\
0.4 \\
0.4 \\
0.4\end{array}$ & $\begin{array}{r}500 \times 500 \\
50 \times 50 \\
50 \times 50 \\
50 \times 50\end{array}$ & $\begin{array}{l}44.9 \\
75.1 \\
65.0 \\
65.3\end{array}$ & $\begin{array}{l}0.25(0.48) \\
0.44(0.56) \\
0.36(0.52) \\
0.37(0.52)\end{array}$ & $\begin{array}{r}5233 \\
639 \\
613 \\
575\end{array}$ & 2.1 \\
\hline A3 & 1700 & 98.2 & $\begin{array}{l}1 \\
2 \\
3 \\
4\end{array}$ & $\begin{array}{l}15 \\
0.8 \\
0.8 \\
0.8\end{array}$ & $\begin{array}{r}1500 \times 1500 \\
100 \times 100 \\
100 \times 100 \\
100 \times 100\end{array}$ & $\begin{array}{l}55.7 \\
82.7 \\
82.7 \\
81.5\end{array}$ & $\begin{array}{l}0.31(0.50) \\
0.48(0.57) \\
0.49(0.57) \\
0.49(0.58)\end{array}$ & $\begin{array}{r}6495 \\
281 \\
260 \\
284\end{array}$ & 6.2 \\
\hline A4 & 1700 & 98.2 & $\begin{array}{l}1 \\
2 \\
3 \\
4\end{array}$ & $\begin{array}{l}15 \\
0.8 \\
0.8 \\
0.8\end{array}$ & $\begin{array}{r}1500 \times 1500 \\
100 \times 100 \\
100 \times 100 \\
100 \times 100\end{array}$ & $\begin{array}{l}52.9 \\
79.0 \\
82.0 \\
80.8\end{array}$ & $\begin{array}{l}0.29(0.49) \\
0.45(0.55) \\
0.48(0.57) \\
0.48(0.57)\end{array}$ & $\begin{array}{r}6164 \\
264 \\
265 \\
250\end{array}$ & 6.4 \\
\hline Z1 & 1550 & 97.5 & $\begin{array}{l}1 \\
2 \\
3 \\
4\end{array}$ & $\begin{array}{l}5 \\
0.4 \\
0.4 \\
0.4\end{array}$ & $\begin{array}{r}500 \times 500 \\
50 \times 50 \\
50 \times 50 \\
50 \times 50\end{array}$ & $\begin{array}{l}72.7 \\
94.3 \\
94.9 \\
94.6\end{array}$ & $\begin{array}{l}0.43(0.57) \\
0.59(0.62) \\
0.59(0.62) \\
0.59(0.62)\end{array}$ & $\begin{array}{r}8475 \\
251 \\
210 \\
194\end{array}$ & 3.5 \\
\hline $\mathrm{Z} 2$ & 1550 & 97.2 & $\begin{array}{l}1 \\
2 \\
3 \\
4\end{array}$ & $\begin{array}{l}15 \\
0.8 \\
0.8 \\
0.8\end{array}$ & $\begin{array}{r}1500 \times 1500 \\
100 \times 100 \\
100 \times 100 \\
100 \times 100\end{array}$ & $\begin{array}{l}63.5 \\
92.8 \\
92.3 \\
90.5\end{array}$ & $\begin{array}{l}0.37(0.53) \\
0.57(0.60) \\
0.57(0.61) \\
0.55(0.60)\end{array}$ & $\begin{array}{r}7408 \\
344 \\
336 \\
332\end{array}$ & 5.8 \\
\hline $\mathrm{Z} 3$ & 1700 & 97.7 & $\begin{array}{l}1 \\
2 \\
3 \\
4\end{array}$ & $\begin{array}{l}15 \\
0.8 \\
0.8 \\
0.8\end{array}$ & $\begin{array}{r}1500 \times 1500 \\
100 \times 100 \\
100 \times 100 \\
100 \times 100\end{array}$ & $\begin{array}{l}61.6 \\
92.6 \\
92.5 \\
92.8\end{array}$ & $\begin{array}{l}0.36(0.53) \\
0.56(0.60) \\
0.56(0.60) \\
0.55(0.59)\end{array}$ & $\begin{array}{r}7187 \\
157 \\
181 \\
181\end{array}$ & 7.8 \\
\hline $\mathrm{Z4}$ & 1700 & 97.5 & $\begin{array}{l}1 \\
2 \\
3 \\
4\end{array}$ & $\begin{array}{l}15 \\
0.8 \\
0.8 \\
0.8\end{array}$ & $\begin{array}{r}1500 \times 1500 \\
100 \times 100 \\
100 \times 100 \\
100 \times 100\end{array}$ & $\begin{array}{l}73.0 \\
95.4 \\
95.5 \\
95.7\end{array}$ & $\begin{array}{l}0.43(0.56) \\
0.58(0.60) \\
0.60(0.62) \\
0.61(0.63)\end{array}$ & $\begin{array}{r}8507 \\
160 \\
158 \\
172\end{array}$ & 8.3 \\
\hline
\end{tabular}

\footnotetext{
${ }^{\text {a }}$ Measured according to Archimedes' principle and assuming a theoretical density of 3.98 and $6.08\left(\mathrm{~g} / \mathrm{cm}^{3}\right)$ for alumina and zirconia, respectively.

b In parentheses the average CI considering only the values $\geq 0.2$.

c Calculated from EBSD scans 2, 3 and 4 using the equivalent disc diameter method.
}

alumina and zirconia, the Brandon criterion [28] was used to account for the allowed deviation $\Delta \theta$ of experimental values from the theoretical values:

$\Delta \theta=15 \Sigma^{-0.5}$

Special GBs corresponding to given $\Sigma$ values were counted and expressed as a fraction of the total GBs. To improve GB statistics, averaging between data collected from the different scans within the same samples and from different samples of the same material sintered at the same temperature was performed.

In the $\operatorname{EDAX}^{\circledR}$ (TSL) OIM software, the reliability of indexing is expressed by a confidence index (CI) comprised between 0 and 1. It is generally admitted that patterns with a CI value $\geq 0.2$ are almost certainly indexed correctly. In this study, the consistently high CI values (see Table 1) of our EBSD data exclude indexing errors due to pseudo-symmetry, which might occur, e.g. in alumina. Wrong indexing is generally accom- panied by a very low $\mathrm{CI}$, due to the fact that more than one solution with similar likelihood is proposed during the indexing procedure. As a consequence, the quality of EBSD maps would markedly deteriorate, since large grains will typically contain speckled points indexed by any of the pseudo-symmetric orientations (K. Kunze, personal communication). Such features were never observed.

\subsection{Simulation of random spatial models}

In order to compare the distributions of grain misorientation and CSL GBs obtained from the measured samples with the distributions expected for purely random textures, $2 \mathrm{D}$ models containing 50,000 randomly orientated grains (Fig. 3) were simulated for alumina and zirconia. Hexagonal-shaped grains were chosen to approximate the well equilibrated microstructure observed in the samples. The grid of the models consists thus of a regular honeycomb-type arrangement of grains, each 

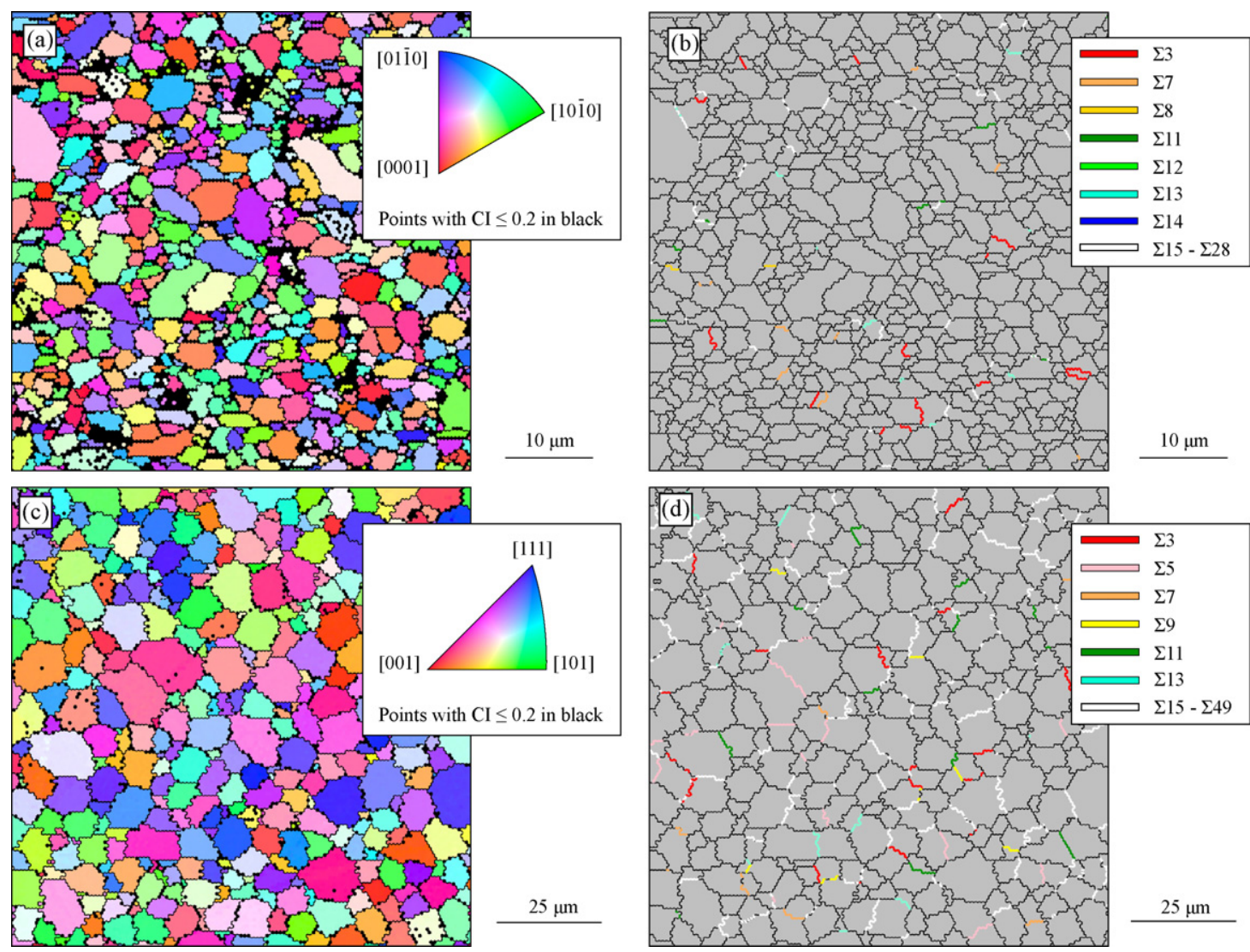

Fig. 2. Inverse pole figure maps showing the crystallographic orientation of the normal to the sample surface (ND) for alumina (a: sample A2 scan 2) and zirconia (c: sample Z2 scan 3), and CSL GB maps (b and d) of the corresponding areas. CSL misorientations with high $\Sigma$ values were grouped for clarity. Since the EDAX ${ }^{\mathbb{R}}$ (TSL) OIM software only highlights GBs between contiguous points, a smooth cleaning up according to the grain dilation method was performed before generating the CSL GB maps.

having six neighbors and $120^{\circ}$ triple junctions. The microstructure corresponds to a cut through a 3D arrangement of Kelvin-polyhedra normal to the two-folded axes. This latter model was used previously by Garbacz and Grabski [29] in 3D simulations of GB character distribution.

A random number calculator was used to generate the Euler angles $\varphi_{1}, \Phi$ and $\varphi_{2}$ necessary to define the orientation of the grains, following the equations first defined by Bunge [24] and used for similar purposes by Pan and Adams [30]:

$\varphi_{1}=2 r_{1} \pi ; \quad \Phi=\cos ^{-1}\left(1-2 r_{2}\right) ; \quad \varphi_{2}=2 r_{3} \pi$

where $r_{1}, r_{2}$ and $r_{3}$ are randomly generated numbers comprised between 0 and 1. Each of the 50,000 Euler triplets was attributed to a grain of the honeycomb microstructure and the grain orientation data were loaded into the $\operatorname{EDAX}^{\circledR}$ (TSL) OIM Analysis software to generate the grain misorientation and CSL distributions.

\section{Results and discussion}

\subsection{Microstructures and textures}

Typical microstructures for alumina and zirconia ceramics sintered at 1550 and $1700{ }^{\circ} \mathrm{C}$ are presented in Fig. 4. The average grain diameter increased by approximately $100 \%$ for zirconia and $200 \%$ for alumina in the samples fired at $1700{ }^{\circ} \mathrm{C}$ (see Table 1). Zirconia specimens are characterized by a well equilibrated equi-dimensional microstructure with a large number of six-sided grains. The remaining pores are located almost exclusively in the interior of the grains. The alumina samples have a wider grain size and shape distribution. Abnormal grain growth, however, was never observed. The porosity is concentrated at GBs and triple junctions. Occasionally, large pores resulting from insufficient powder compaction during the shaping process are encountered.

The LPO for the eight samples (Fig. 5) were calculated from EBSD scans (numbered 1 in Table 1) containing several thousands of grains each. From the texture indexes $J$, which vary between 1.00 and 1.05 , the samples can be considered as texture-free. Nevertheless, small peaks are present in some of the pole figures. In alumina a very weak but obvious LPO was observed, the [ $\left[\begin{array}{llll}0 & 0 & 0 & 1\end{array}\right]$ pole maximum being orientated parallel to the normal direction (ND). This is probably due to the reorientation of the platelet-shaped crystallites present in the initial powder (see Fig. 1a) in response to the uniaxial pressing of the green bodies. The LPO of zirconia is purely random, except for sample Z3, for which a very weak [ [ 1111$]$ pole maximum is orientated parallel to ND. 
Table 2

Coincidence rotations used to determine CSL GBs in rhomboedral alumina [27] and cubic zirconia [25]

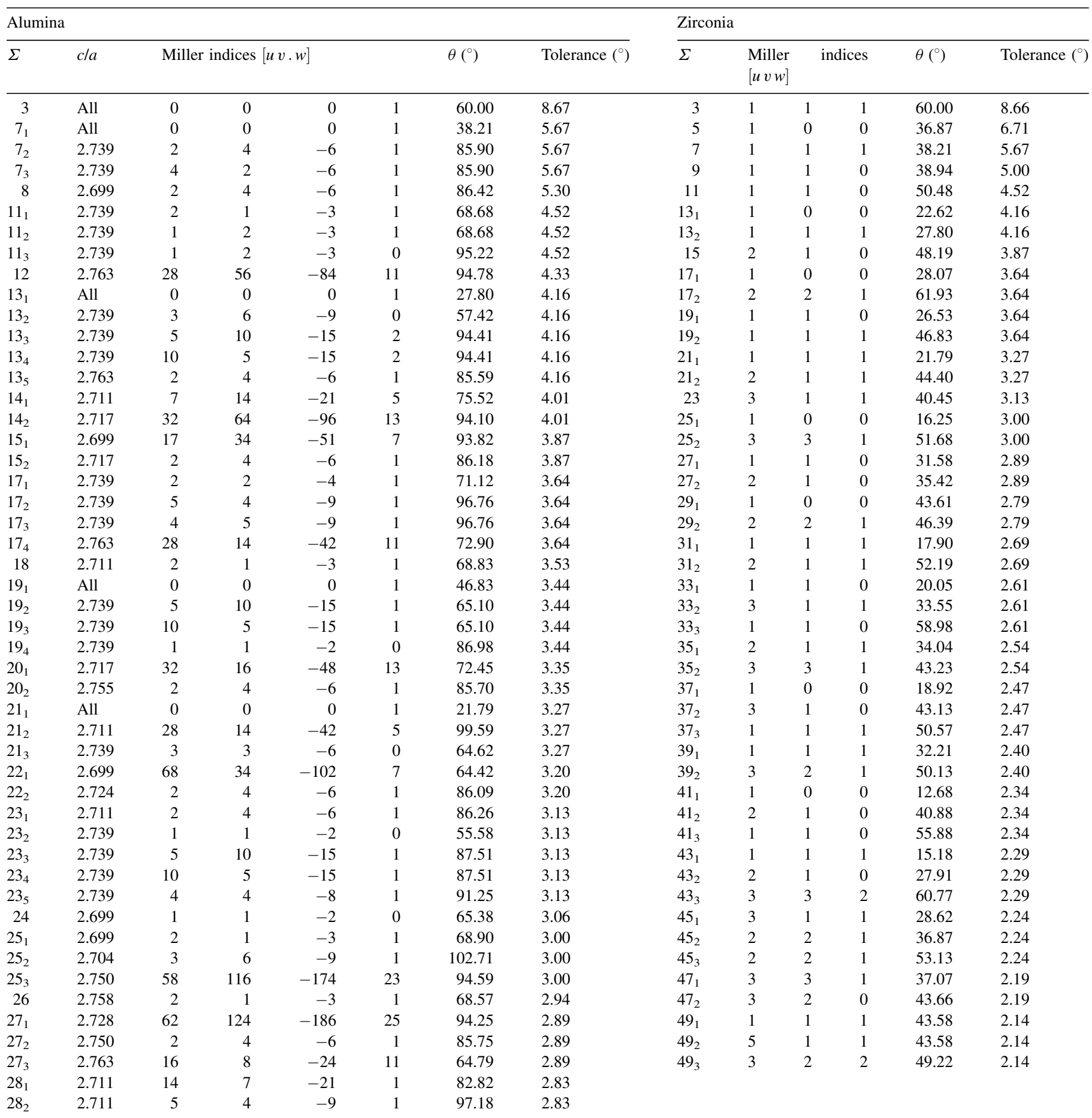

Subscripts are used to differentiate angle/axis pairs characterized by the same multiplicity index $\Sigma$.

\subsection{Grain misorientation distributions}

The grain misorientation distributions were calculated up to $107.5^{\circ}$ for alumina and $62.8^{\circ}$ for zirconia, i.e. the limits imposed by symmetry. The histograms of the measured misorientation angles for both alumina and zirconia were compared with the model random distributions using the Kolmogorov-Smirnov test [31]. Using all misorientations, i.e. without prior classification, the measured distributions cannot be distinguished from the random distribution even as far down as the $\alpha=0.2$ level. The same holds for histograms of the same data with a restricted number of classes (Fig. 6).

Visual inspection of the histograms for the measured alumina grain misorientation distributions shows, however, that the positions of the relative maxima and minima are not completely random. There are relative maxima in both 

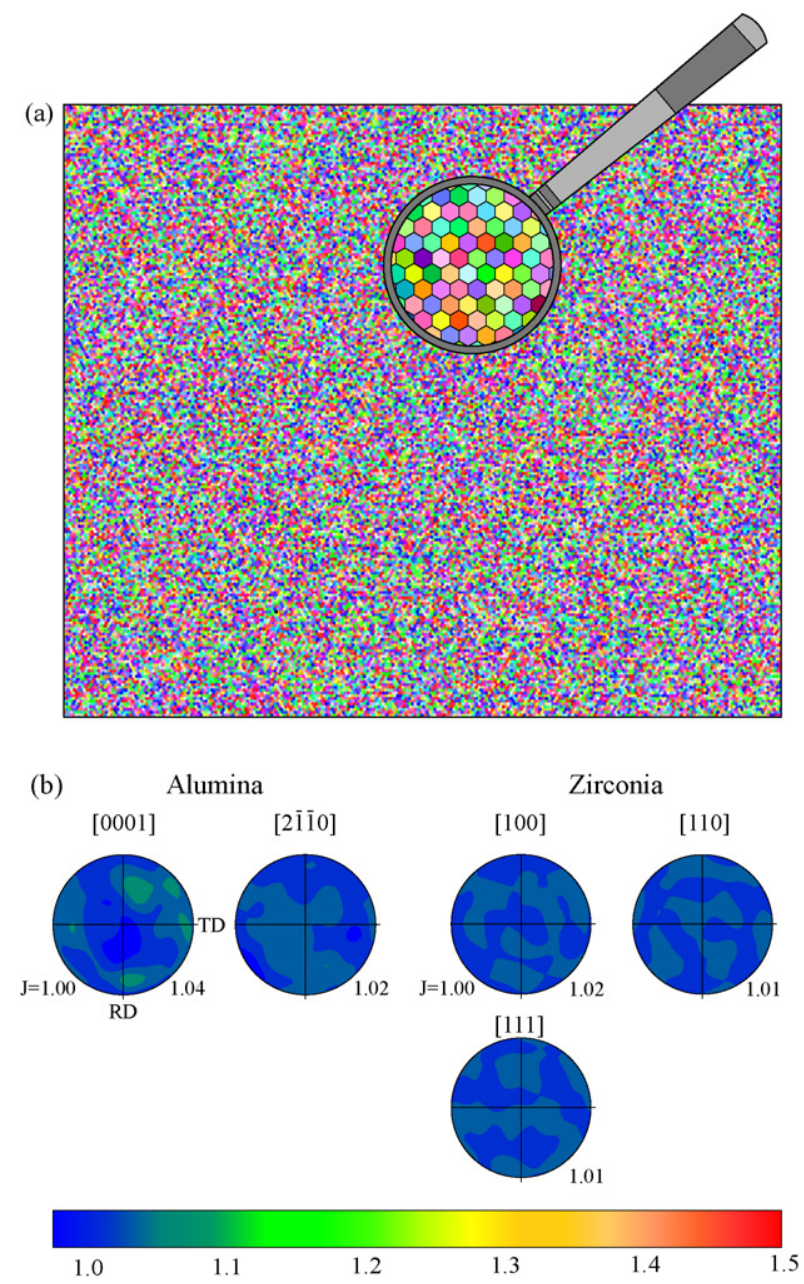

Fig. 3. (a) Map of the simulated spatial model containing 50,000 hexagonalshaped and randomly orientated grains. (b) Pole figures for the simulated textures with crystallographic properties corresponding to alumina and zirconia. Pole figures are represented on upper hemisphere equal area projections. The number on the bottom right of each plot is the maximum density expressed in multiples of uniform distribution (see scale bar). For each sample, the texture index $J$, calculated for an expansion index of 22 and a Gaussian half-width of $15^{\circ}$ is shown on the bottom left. TD, RD and ND (page normal) are indicated for the first plot only. Texture indexes $J$ of 1.00 for both alumina and zirconia indicates that the simulated spatial models are texture-free.

distributions at around $50^{\circ}, 60^{\circ}$, and between $82.5^{\circ}$ and $92.5^{\circ}$. Relative maxima for similar misorientation angles are also found in other misorientation distributions for alumina published so far (e.g. Refs. $[7,19])$. All samples had, similar to the present ones, a weak texture, which may be the reason for these characteristic maxima (see Section 3.3). The increase in temperature and the associated increase in grain size have no effect in the distribution observed in the present samples, i.e. the details of the distributions (relative maxima) remain the same. This is consistent with the distributions extracted from Monte Carlo grain growth simulations of Hassold et al. [32], which showed that the fraction of CSL GBs does not change with time, i.e. with increasing grain size, except for low angle GBs $(\Sigma 1)$.

The misorientation distributions of the zirconia average samples show no relative maxima and the differences between the distributions are as small as the differences between measured and random distributions.

\subsection{CSL grain boundary distributions}

\subsubsection{Validity of the simulated spatial models}

Two methods are described in the literature to obtain random CSL GB distributions for microstructures consisting of cubic phases. Model distributions are either calculated from randomly generated pairs of grain orientations or they are extracted from a plane or space filling arrangement of randomly orientated grains, as was done in the present study. It has been shown that the two methods are not equivalent [29] and that the values obtained from random spatial models built with Kelvin polyhedra-shaped grains fit better with measured random grain misorientation and CSL GB distributions. The 3D model, however, does also not reflect truly the geometry of the EBSD measurements, which are obtained from a 2D cut through the 3D microstructure. Therefore, we decided to extract the random CSL GB distribution from a 2D honeycomb microstructure. The CSL GB frequencies obtained for zirconia are close to the values obtained by Garbacz and Grabski [29]. For $\Sigma$ values up to 37 , the differences are less than $10 \mathrm{rel} \%$.

With regards to alumina, there are no data given in the literature for the theoretical CSL distribution in a random texture with trigonal symmetry. However, the analytical expression given by Morawiec et al. [33] to calculate the number fraction of individual CSL GBs, although based on randomly distributed orientation matrices and not on a physical random microstructure, can be used as a rough guideline to test the validity of our simulated $2 \mathrm{D}$ model. According to these authors, the calculated number fraction of CSL GBs with given $\Sigma, f_{\mathrm{C}} \Sigma$, is given by

$f_{\mathrm{C}} \Sigma=\frac{\lambda N^{2}}{\pi N(g)}(\Delta \theta-\sin \Delta \theta)$

$N$ is the order of the subgroup of the crystallographic point symmetry containing only rotations (six for trigonal point groups), $\lambda$ and $N(g)$ are parameters taking into account the orientation of the CSL misorientation axis relative to the crystal rotation axis and $\Delta \theta$ is the angle given by the Brandon criterion. The calculation of $f_{\mathrm{C}} \Sigma$ is complicated by the $c / a$ dependence of the CSL. Therefore, only the calculated frequencies of the common (unspecific) CSL misorientations are presented (Table 3). They are all larger than the fractions $f_{\mathrm{S}} \Sigma$ obtained from the present 2D random model, an observation already made for the cubic system [29]. The details and the full set of results will be presented in a forthcoming paper.

The good correspondence between the calculated and simulated values for both alumina and zirconia is an indication that our simulated random CSL GB distributions are reliable.

\subsubsection{CSL grain boundary distributions in measurements and simulated models}

3.3.2.1. Alumina. In alumina the total number fraction of CSL GBs is $3.98 \pm 0.2 \%$ for the average sample sintered at $1550{ }^{\circ} \mathrm{C}$ and $4.44 \pm 0.1 \%$ for the one sintered at $1700{ }^{\circ} \mathrm{C}$ (Table 4). 

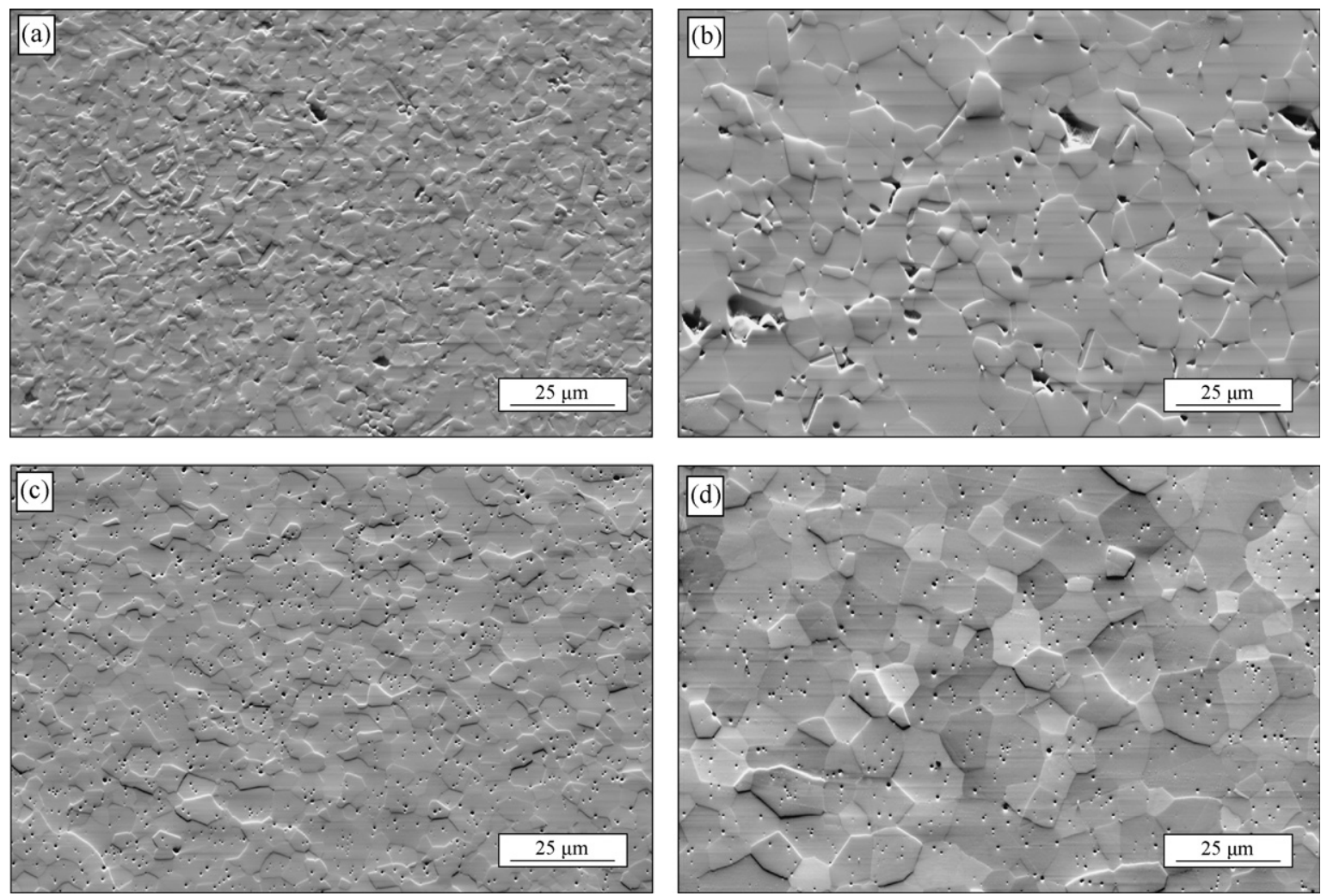

Fig. 4. SEM forescattered electron images showing typical microstructures of alumina (a and b) and zirconia (c and d) samples. Contrast and topography from one grain to the next express changes in crystallographic orientations. The samples displayed in (a) and (c) were sintered at $1550{ }^{\circ} \mathrm{C}$ and those in (b) and (d) at $1700{ }^{\circ} \mathrm{C}$.

These values are significantly higher than the number fraction of CSL GBs for the simulated random model, i.e. 2.67\%. The GB character distribution (Fig. 7a) shows a predominance of $\Sigma 3 \mathrm{GBs}$ in the measured samples. The other CSL GBs, however, also contribute to the differences between the measurements and the spatial model, as shown by the relative difference parameter $\eta$ :

$$
\eta=\frac{f_{\mathrm{M}} \Sigma-f_{\mathrm{S}} \Sigma}{f_{\mathrm{S}} \Sigma} \times 100
$$

where $f_{\mathrm{M}} \Sigma$ and $f_{\mathrm{S}} \Sigma$ are the $\Sigma$ number fractions relative to the total number of GBs for the measured average samples and
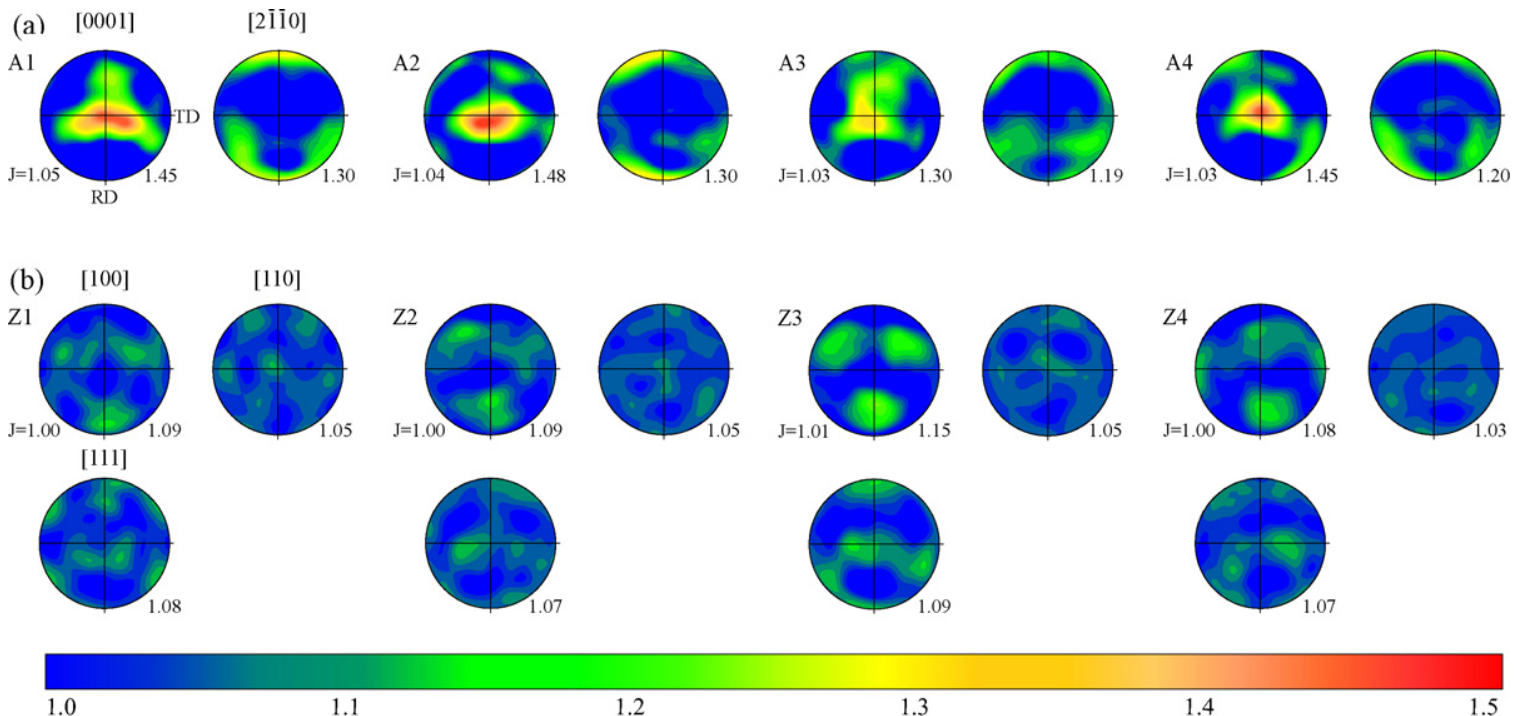

1.1

1.2

1.3

1.4

1.5

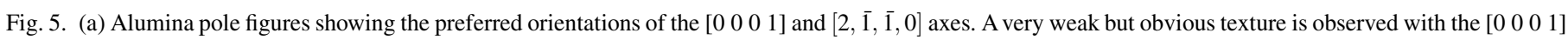

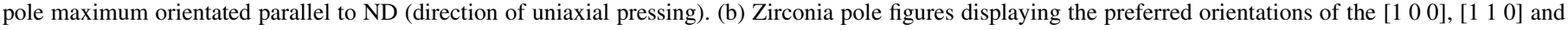
$\left[\begin{array}{lll}1 & 1 & 1\end{array}\right]$ axes. The constantly small $J$ index values indicate absence of significant texture. Pole figures are represented on upper hemisphere equal area projections and were calculated from the data of the scans labeled 1 in Table 1. Symbols and reference axes as in Fig. 3. 

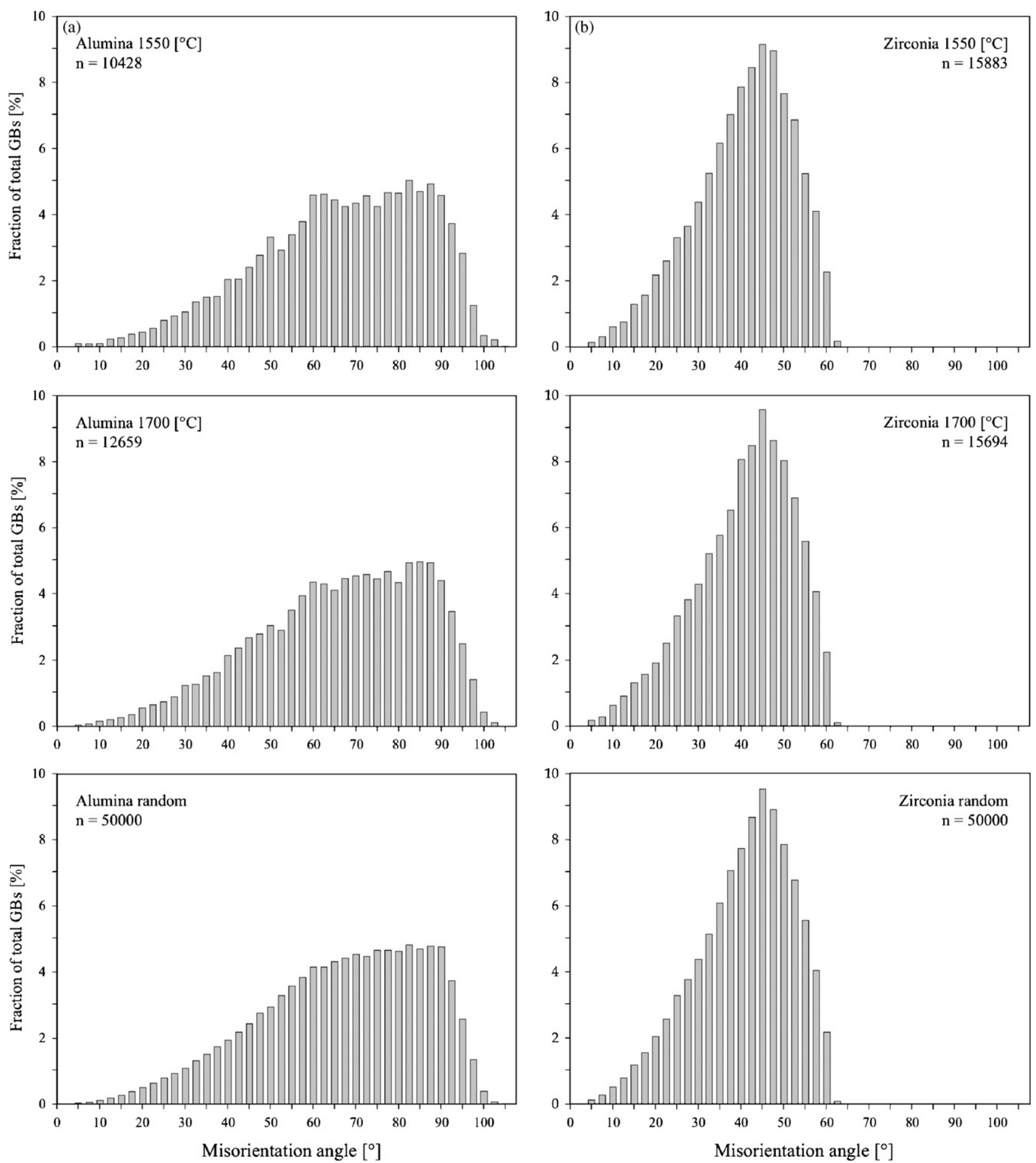

Fig. 6. Histograms of misorientation angles for (a) alumina and (b) zirconia ceramics sintered at 1550 and $1700{ }^{\circ} \mathrm{C} ; n=$ number of grains. The distribution for the spatial models simulated for 50,000 randomly orientated grains is indicated for comparison.

simulated random models, respectively. To avoid bias due to insufficient GB sampling, calculations according to Eq. (4) was limited to CSL GBs for which $f_{\mathrm{M}} \Sigma>0.1 \%$.

For the alumina samples sintered at $1550{ }^{\circ} \mathrm{C}$, all except one of the $f_{\mathrm{M}} \Sigma$ 's are larger than the $f_{\mathrm{S}} \Sigma$ 's (relative difference $\eta>0$ ) (Fig. 8a). However, $\eta$ is, for most GBs less than the $1-\sigma$ error calculated from counting statistics. The largest difference is for the $\Sigma 3 \mathrm{~GB}$ fraction. In the literature, high $\Sigma 3$ number fractions are also reported for REE-doped alumina samples characterized by very weak textures $[7,34]$ and for alumina produced by gel-casting [35]. In this latter study, the idiomorphic and platelet morphology (normal to the $\left[\begin{array}{llll}0 & 0 & 0 & 1\end{array}\right]$ axis) of the initial particles, which were deposited in an oriented manner onto a substrate, was interpreted to be responsible for

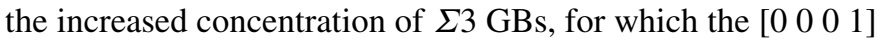
axis is the misorientation axis. The starting powder used in the 
Table 3

Fractions $f_{\mathrm{C}} \Sigma(\%)$ of CSL GBs calculated according to Eq. (3) for the common (unspecific) coincidence misorientations in alumina

\begin{tabular}{rrrcc}
\hline$\Sigma$ & $\lambda$ & $N$ & $f_{\mathrm{C}} \Sigma$ & $f_{\mathrm{S}} \Sigma$ \\
\hline 3 & 1 & 6 & 0.110 & 0.087 \\
$77_{1}$ & 1 & 3 & 0.061 & 0.049 \\
$13_{1}$ & 1 & 3 & 0.024 & 0.016 \\
$19_{1}$ & 1 & 3 & 0.014 & 0.013 \\
$21_{1}$ & 1 & 3 & 0.012 & 0.011
\end{tabular}

Fractions obtained from the simulated random 2D spatial model $\left(f_{\mathrm{S}} \Sigma\right)$ are shown for comparison.

present investigation also consists of platelet-shaped crystallites (see Fig. 1a) and the pressure applied during the manufacturing of the green bodies might, therefore, explain the increase in $\Sigma 3$ GBs.

For the alumina samples sintered at $1700{ }^{\circ} \mathrm{C}$, more than $80 \%$ of the $f_{\mathrm{M}} \Sigma$ 's are larger than the $f_{\mathrm{S}} \Sigma$ 's. Two thirds of them show a relative difference $\eta>100 \%$, with again a high $\Sigma 3$ number fraction. The deviation relative to the random model is, therefore, statistically significant.

About $65 \%$ of the CSL misorientations for which $f_{\mathrm{M}} \Sigma$ is $>0.1 \%$ in one or two of the samples show an increase relative to the samples sintered at the lower temperature, i.e. the relative difference $\xi$, defined as follows, is larger than 0 :

$\xi=\frac{f_{\mathrm{M}} \Sigma_{1700}-f_{\mathrm{M}} \Sigma_{1550}}{f_{\mathrm{M}} \Sigma_{1550}} \times 100$

where $f_{\mathrm{M}} \Sigma_{1550}$ and $f_{\mathrm{M}} \Sigma_{1700}$ are the measured $\Sigma$ number fractions relative to the total number of GBs for the average samples sintered at 1550 and $1700{ }^{\circ} \mathrm{C}$, respectively. Increase or decrease of the amount of CSL GBs with sintering temperature seems to be crystallographically controlled. The fractions of CSL misorientations with rotation axes parallel or slightly inclined with respect to the basal plane, i.e. normal to the $\left[\begin{array}{llll}0 & 0 & 0 & 1\end{array}\right]$ axis, decrease with temperature, whereas the misorientations with rotation axes normal to the basal plane, i.e. parallel to the $\left[\begin{array}{llll}0 & 0 & 0 & 1\end{array}\right]$ axis, increase (Fig. 9). This may be explained by the anisotropy of physical parameters that influence grain growth, such as GB mobility. Prism faces (parallel to the $\left[\begin{array}{llll}0 & 0 & 0 & 1\end{array}\right]$ axis) tend to move faster (along the $[2, \overline{1}, \overline{1}, 0]$ axis) than the basal planes (along the [l $\left.\begin{array}{llll}0 & 0 & 1\end{array}\right]$ axis) [36]. Therefore, the surface ratio $S_{\text {prism }} / S_{\text {basal }}$ decreases with increasing grain size, whereas the number fraction ratio $f_{\text {prism }} / f_{\text {basal }}$ increases. As GB planes for grain misorientations with the CSL misorientation axes parallel to the $\left[\begin{array}{llll}0 & 0 & 0 & 1\end{array}\right]$ axis are likely to be also

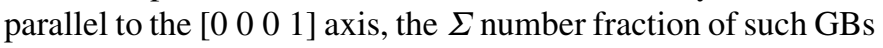
is expected to increase, as observed.

3.3.2.2. Zirconia. Zirconia globally shows higher $f_{\mathrm{M}} \Sigma$ 's compared to alumina, as expected for a phase with cubic symmetry. The GB character distribution shows that the number fraction of CSL GBs decreases exponentially with increasing $\Sigma$, as predicted by the random 2D model (Fig. 7b). The total fractions of CSL GBs are very similar for both average samples, i.e. $17.82 \% \pm 0.1 \%$ for the average sample sintered at
$1550{ }^{\circ} \mathrm{C}$ and $16.94 \% \pm 0.8 \%$ for the one sintered at $1700{ }^{\circ} \mathrm{C}$ (Table 4). These values are $4.59 \%$ and $3.71 \%$ higher than the total fraction of CSL GBs predicted from the random 2D model, even though the Kolmogorov-Smirnov test indicates that the measured distributions cannot be distinguished from the latter.

The relative difference $\eta$ of three fourths of the CSL GBs (considering only $f_{\mathrm{M}} \Sigma>0.1 \%$ ) in zirconia (Fig. 8b) decreases with higher sintering temperature. None of the CSL GBs in the $1550{ }^{\circ} \mathrm{C}$ average sample and only three in the $1700{ }^{\circ} \mathrm{C}$ average sample $\left(\Sigma 11, \Sigma 13_{1}\right.$ and $\left.\Sigma 33_{1}\right)$ have number fractions that differ by more than $100 \%$ from the random model.

About $65 \%$ of the CSL misorientations for which $f_{\mathrm{M}} \Sigma$ 's is larger than $0.1 \%$ in one or two of the samples show a decrease relative to the samples sintered at the lower temperature $(\xi$ negative, not presented), but only two show differences larger than $50 \%$.

\subsubsection{Triple junction character and prominence factors in zirconia}

The number of CSL GBs in zirconia is a sizeable amount of the total number of GBs present in the samples, which increases the probability that two or three CSL GBs meet at a triple junction. In both average zirconia samples, the triple junction character, i.e. the fractions $J_{n}$ of junctions with n CSL GBs $(n=0,1,2,3)$, fit relatively well with simulated triple junction distribution curves reported in the literature [37]. GBs meeting at a triple junction follow the misorientation conservation law, which states that the total misorientation around each triple junction has to be zero. In terms of the CSL theory, the general misorientation law becomes the sigma combination rule:

$\Sigma a \Sigma b=m^{2} \Sigma c$

where the $\Sigma$-terms represent numerical $\Sigma$-values and m can be any common divisor of $a$ and $b$.

Schuh et al. [38] have presented a generalized description of the GB character distribution for fcc metals based on these conservation laws. The microstructure of fcc metals with low to medium stacking fault energies is dominated by $\Sigma 3 \mathrm{GBs}$, which are the result of annealing twinning. The larger the number of $\Sigma 3 \mathrm{GBs}$ in a microstructure the higher is the likelihood that two of them meet at a triple junction. The third GB is determined by the sigma combination rule and must be a $\Sigma 9(m=1)$ or a $\Sigma 1$ $(m=3)$ GB. A $\Sigma 3$ and $\Sigma 9$ meeting at a triple junction fix the third GB to be a $\Sigma 3(m=3)$ or a $\Sigma 27(m=1)$. The number fractions of these GBs are thus related. The prominence of $\Sigma 3$, $\Sigma 9$ and $\Sigma 27$ GBs may be expressed by so called twin prominence factors $\mathrm{A}_{3}$ and $A_{9}$ [38]:

$A_{3}=\frac{f \Sigma 3}{f \Sigma 3+f \Sigma 9+f \Sigma 27} \quad$ and $\quad A_{9}=\frac{f \Sigma 9}{f \Sigma 9+f \Sigma 27}$

with $f \Sigma i$ representing the number fraction for $\Sigma$ GBs of type $i$. As expected, these factors have similar values and for the samples analyzed by Schuh et al. [38] they are between 0.5 and 0.9 , with a maximum at 0.75 . Furthermore, in most samples $A_{3} \approx A_{9}$, so that one parameter is sufficient to describe a large part of the CSL GB population. 
Table 4

$\Sigma$ number fractions $(\%)$ of the total GBs for the individual and average samples, as well as for the simulated random models

\begin{tabular}{|c|c|c|c|c|c|c|c|c|c|c|c|c|c|c|c|}
\hline \multicolumn{8}{|c|}{ Alumina } & \multicolumn{8}{|c|}{ Zirconia } \\
\hline$\Sigma$ & $f_{\mathrm{M}} \Sigma_{A_{1}}$ & $f_{\mathrm{M}} \Sigma_{A_{2}}$ & $f_{\mathrm{M}} \Sigma_{1550}$ & $f_{\mathrm{M}} \Sigma_{A_{3}}$ & $f_{\mathrm{M}} \Sigma_{A_{4}}$ & $f_{\mathrm{M}} \Sigma_{1700}$ & $f_{\mathrm{S}} \Sigma$ & $\Sigma$ & $f_{\mathrm{M}} \Sigma_{\mathrm{Z} 1}$ & $f_{\mathrm{M}} \Sigma_{\mathrm{Z} 2}$ & $f_{\mathrm{M}} \Sigma_{1550}$ & $f_{\mathrm{M}} \Sigma_{\mathrm{Z} 3}$ & $f_{\mathrm{M}} \Sigma_{\mathrm{Z} 4}$ & $f_{\mathrm{M}} \Sigma_{1700}$ & $f_{\mathrm{S}} \Sigma$ \\
\hline 3 & 0.49 & 0.79 & 0.64 & 0.65 & 0.69 & 0.67 & 0.09 & 3 & 1.89 & 2.00 & 1.97 & 1.74 & 1.91 & 1.82 & 1.54 \\
\hline $7_{1}$ & 0.06 & 0.04 & 0.05 & 0.05 & 0.16 & 0.10 & 0.05 & 5 & 1.49 & 1.59 & 1.56 & 1.03 & 1.75 & 1.38 & 1.08 \\
\hline $7_{2}$ & 0.04 & 0.07 & 0.05 & 0.05 & 0.11 & 0.08 & 0.06 & 7 & 0.86 & 0.83 & 0.84 & 1.11 & 0.58 & 0.85 & 0.85 \\
\hline $7_{3}$ & 0.41 & 0.31 & 0.36 & 0.70 & 0.58 & 0.64 & 0.31 & 9 & 1.10 & 1.10 & 1.10 & 0.79 & 1.08 & 0.93 & 0.87 \\
\hline 8 & 0.13 & 0.22 & 0.17 & 0.35 & 0.05 & 0.20 & 0.12 & 11 & 1.41 & 1.02 & 1.15 & 1.27 & 1.50 & 1.38 & 0.67 \\
\hline $11_{1}$ & 0.15 & 0.07 & 0.11 & 0.00 & 0.11 & 0.05 & 0.10 & $13_{1}$ & 0.31 & 0.30 & 0.31 & 0.40 & 1.00 & 0.69 & 0.25 \\
\hline $11_{2}$ & 0.17 & 0.22 & 0.20 & 0.15 & 0.32 & 0.23 & 0.15 & $13_{2}$ & 0.71 & 0.30 & 0.43 & 0.40 & 0.25 & 0.32 & 0.32 \\
\hline $11_{3}$ & 0.13 & 0.26 & 0.20 & 0.10 & 0.16 & 0.13 & 0.15 & 15 & 1.18 & 1.13 & 1.15 & 1.03 & 0.17 & 0.61 & 0.79 \\
\hline 12 & 0.00 & 0.02 & 0.01 & 0.00 & 0.00 & 0.00 & 0.02 & $17_{1}$ & 0.39 & 0.26 & 0.31 & 0.08 & 0.33 & 0.20 & 0.13 \\
\hline $13_{1}$ & 0.06 & 0.07 & 0.07 & 0.00 & 0.00 & 0.00 & 0.02 & $17_{2}$ & 0.79 & 0.64 & 0.69 & 0.40 & 0.42 & 0.41 & 0.34 \\
\hline $13_{2}$ & 0.15 & 0.18 & 0.16 & 0.10 & 0.11 & 0.10 & 0.12 & $19_{1}$ & 0.39 & 0.26 & 0.31 & 0.16 & 0.50 & 0.32 & 0.26 \\
\hline $13_{3}$ & 0.06 & 0.02 & 0.04 & 0.05 & 0.05 & 0.05 & 0.01 & $19_{2}$ & 0.24 & 0.23 & 0.23 & 0.16 & 0.25 & 0.20 & 0.18 \\
\hline $13_{4}$ & 0.13 & 0.15 & 0.14 & 0.25 & 0.11 & 0.18 & 0.12 & $21_{1}$ & 0.16 & 0.26 & 0.23 & 0.08 & 0.33 & 0.20 & 0.15 \\
\hline $13_{5}$ & 0.04 & 0.00 & 0.02 & 0.05 & 0.05 & 0.05 & 0.02 & $21_{2}$ & 0.24 & 0.34 & 0.31 & 0.71 & 0.50 & 0.61 & 0.49 \\
\hline $14_{1}$ & 0.11 & 0.11 & 0.11 & 0.25 & 0.26 & 0.26 & 0.11 & 23 & 0.24 & 0.53 & 0.43 & 0.79 & 0.67 & 0.73 & 0.41 \\
\hline $14_{2}$ & 0.00 & 0.00 & 0.00 & 0.00 & 0.05 & 0.03 & 0.01 & $25_{1}$ & 0.16 & 0.19 & 0.18 & 0.16 & 0.17 & 0.16 & 0.09 \\
\hline $15_{1}$ & 0.11 & 0.09 & 0.10 & 0.05 & 0.21 & 0.13 & 0.05 & $25_{2}$ & 0.16 & 0.61 & 0.46 & 0.24 & 0.42 & 0.32 & 0.37 \\
\hline $15_{2}$ & 0.00 & 0.04 & 0.02 & 0.00 & 0.05 & 0.03 & 0.05 & $27_{1}$ & 0.31 & 0.19 & 0.23 & 0.32 & 0.25 & 0.28 & 0.15 \\
\hline $17_{1}$ & 0.17 & 0.07 & 0.12 & 0.10 & 0.05 & 0.08 & 0.08 & $27_{2}$ & 0.47 & 0.53 & 0.51 & 0.47 & 0.33 & 0.41 & 0.33 \\
\hline $17_{2}$ & 0.04 & 0.09 & 0.07 & 0.05 & 0.05 & 0.05 & 0.04 & $29_{1}$ & 0.16 & 0.11 & 0.13 & 0.16 & 0.08 & 0.12 & 0.04 \\
\hline $17_{3}$ & 0.11 & 0.09 & 0.10 & 0.10 & 0.21 & 0.16 & 0.07 & $29_{2}$ & 0.00 & 0.42 & 0.28 & 0.47 & 0.33 & 0.41 & 0.29 \\
\hline $17_{4}$ & 0.00 & 0.02 & 0.01 & 0.00 & 0.00 & 0.00 & 0.02 & $31_{1}$ & 0.16 & 0.23 & 0.20 & 0.16 & 0.08 & 0.12 & 0.07 \\
\hline 18 & 0.00 & 0.02 & 0.01 & 0.05 & 0.00 & 0.03 & 0.03 & $31_{2}$ & 0.55 & 0.42 & 0.46 & 0.47 & 0.17 & 0.32 & 0.28 \\
\hline $19_{1}$ & 0.00 & 0.00 & 0.00 & 0.05 & 0.00 & 0.03 & 0.01 & $33_{1}$ & 0.08 & 0.11 & 0.10 & 0.24 & 0.75 & 0.49 & 0.14 \\
\hline $19_{2}$ & 0.11 & 0.13 & 0.12 & 0.10 & 0.05 & 0.08 & 0.06 & $33_{2}$ & 0.39 & 0.30 & 0.33 & 0.40 & 0.33 & 0.36 & 0.25 \\
\hline $19_{3}$ & 0.00 & 0.04 & 0.02 & 0.15 & 0.05 & 0.10 & 0.02 & $33_{3}$ & 0.39 & 0.08 & 0.18 & 0.08 & 0.17 & 0.12 & 0.12 \\
\hline $19_{4}$ & 0.06 & 0.02 & 0.04 & 0.05 & 0.05 & 0.05 & 0.03 & $35_{1}$ & 0.31 & 0.30 & 0.31 & 0.32 & 0.25 & 0.28 & 0.23 \\
\hline $20_{1}$ & 0.11 & 0.18 & 0.14 & 0.05 & 0.11 & 0.08 & 0.07 & $35_{2}$ & 0.31 & 0.38 & 0.36 & 0.08 & 0.25 & 0.16 & 0.24 \\
\hline $20_{2}$ & 0.00 & 0.02 & 0.01 & 0.00 & 0.00 & 0.00 & 0.01 & $37_{1}$ & 0.16 & 0.08 & 0.10 & 0.08 & 0.08 & 0.08 & 0.01 \\
\hline $21_{1}$ & 0.04 & 0.00 & 0.02 & 0.05 & 0.05 & 0.05 & 0.01 & $37_{2}$ & 0.31 & 0.11 & 0.18 & 0.16 & 0.25 & 0.20 & 0.21 \\
\hline $21_{2}$ & 0.13 & 0.02 & 0.08 & 0.10 & 0.05 & 0.08 & 0.06 & $37_{3}$ & 0.39 & 0.19 & 0.26 & 0.08 & 0.25 & 0.16 & 0.03 \\
\hline $21_{3}$ & 0.00 & 0.02 & 0.01 & 0.00 & 0.00 & 0.00 & 0.01 & $39_{1}$ & 0.08 & 0.15 & 0.13 & 0.16 & 0.08 & 0.12 & 0.02 \\
\hline $22_{1}$ & 0.06 & 0.07 & 0.07 & 0.30 & 0.05 & 0.18 & 0.06 & $39_{2}$ & 0.31 & 0.49 & 0.43 & 0.40 & 0.25 & 0.32 & 0.39 \\
\hline $22_{2}$ & 0.00 & 0.00 & 0.00 & 0.00 & 0.00 & 0.00 & 0.00 & $41_{1}$ & 0.08 & 0.04 & 0.05 & 0.08 & 0.17 & 0.12 & 0.04 \\
\hline $23_{1}$ & 0.02 & 0.00 & 0.01 & 0.00 & 0.05 & 0.03 & 0.01 & $41_{2}$ & 0.31 & 0.19 & 0.23 & 0.32 & 0.08 & 0.20 & 0.17 \\
\hline $23_{2}$ & 0.04 & 0.07 & 0.05 & 0.05 & 0.00 & 0.03 & 0.02 & $41_{3}$ & 0.00 & 0.04 & 0.03 & 0.00 & 0.25 & 0.12 & 0.05 \\
\hline $23_{3}$ & 0.02 & 0.04 & 0.03 & 0.05 & 0.05 & 0.05 & 0.06 & $43_{1}$ & 0.00 & 0.08 & 0.05 & 0.00 & 0.00 & 0.00 & 0.03 \\
\hline $23_{4}$ & 0.09 & 0.09 & 0.09 & 0.05 & 0.16 & 0.10 & 0.04 & $43_{2}$ & 0.24 & 0.23 & 0.23 & 0.08 & 0.17 & 0.12 & 0.17 \\
\hline $23_{5}$ & 0.09 & 0.04 & 0.06 & 0.00 & 0.11 & 0.05 & 0.06 & $43_{3}$ & 0.08 & 0.11 & 0.10 & 0.16 & 0.25 & 0.20 & 0.09 \\
\hline 24 & 0.06 & 0.00 & 0.03 & 0.00 & 0.00 & 0.00 & 0.03 & $45_{1}$ & 0.00 & 0.19 & 0.13 & 0.16 & 0.08 & 0.12 & 0.18 \\
\hline $25_{1}$ & 0.04 & 0.00 & 0.02 & 0.00 & 0.00 & 0.00 & 0.01 & $45_{2}$ & 0.31 & 0.23 & 0.26 & 0.24 & 0.08 & 0.16 & 0.16 \\
\hline $25_{2}$ & 0.09 & 0.13 & 0.11 & 0.05 & 0.11 & 0.08 & 0.05 & $45_{3}$ & 0.16 & 0.11 & 0.13 & 0.24 & 0.42 & 0.32 & 0.17 \\
\hline $25_{3}$ & 0.02 & 0.02 & 0.02 & 0.00 & 0.05 & 0.03 & 0.01 & $47_{1}$ & 0.08 & 0.11 & 0.10 & 0.08 & 0.25 & 0.16 & 0.16 \\
\hline 26 & 0.00 & 0.07 & 0.03 & 0.00 & 0.05 & 0.03 & 0.05 & $47_{2}$ & 0.08 & 0.15 & 0.13 & 0.00 & 0.00 & 0.00 & 0.14 \\
\hline $27_{1}$ & 0.00 & 0.09 & 0.04 & 0.05 & 0.00 & 0.03 & 0.05 & $49_{1}$ & 0.08 & 0.08 & 0.08 & 0.00 & 0.00 & 0.00 & 0.00 \\
\hline $27_{2}$ & 0.00 & 0.07 & 0.03 & 0.10 & 0.00 & 0.05 & 0.04 & $49_{2}$ & 0.08 & 0.26 & 0.20 & 0.24 & 0.08 & 0.16 & 0.13 \\
\hline $27_{3}$ & 0.06 & 0.00 & 0.03 & 0.00 & 0.16 & 0.08 & 0.04 & $49_{3}$ & 0.16 & 0.34 & 0.28 & 0.00 & 0.25 & 0.12 & 0.13 \\
\hline $28_{1}$ & 0.06 & 0.09 & 0.08 & 0.00 & 0.00 & 0.00 & 0.04 & & & & & & & & \\
\hline $28_{2}$ & 0.06 & 0.04 & 0.05 & 0.00 & 0.00 & 0.00 & 0.04 & & & & & & & & \\
\hline Total & 3.75 & 4.21 & 3.98 & 4.33 & 4.55 & 4.44 & 2.67 & & 17.75 & 17.85 & 17.82 & 16.14 & 17.79 & 16.94 & 13.23 \\
\hline
\end{tabular}

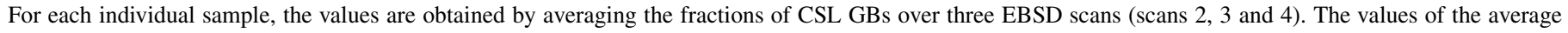
samples are calculated by summing all CSL GBs occurring in the same material for a given sintering temperature.

Zirconia has also an fcc structure, but with high stacking fault energy, which explains its rather low CSL GB fraction (17.5\%). This value is at the lower end of the range investigated by Schuh et al. [38]. The prominence factors calculated both for the zirconia average samples $\left(A_{3,1550}=0.52, \quad A_{3,1700}=0.53\right.$, $\left.A_{9,1550}=0.60, A_{9,1700}=0.57\right)$ and for the simulated random model $\left(A_{3, \mathrm{~S}}=0.53, A_{9, \mathrm{~S}}=0.64\right)$ fall in the range given for fcc metals. Therefore, the limit of 0.5 given by Schuh et al. [38] might be a too small lower bound for the twin prominence factors in fcc metals and the range given by Gertsman and Tangri [39] and Palumbo et al. [40] are probably more appropriate to describe microstructures dominated by annealing twinning.

Parameters similar to the twin prominence factors may be used to visualize differences between the measured and a 
(a)
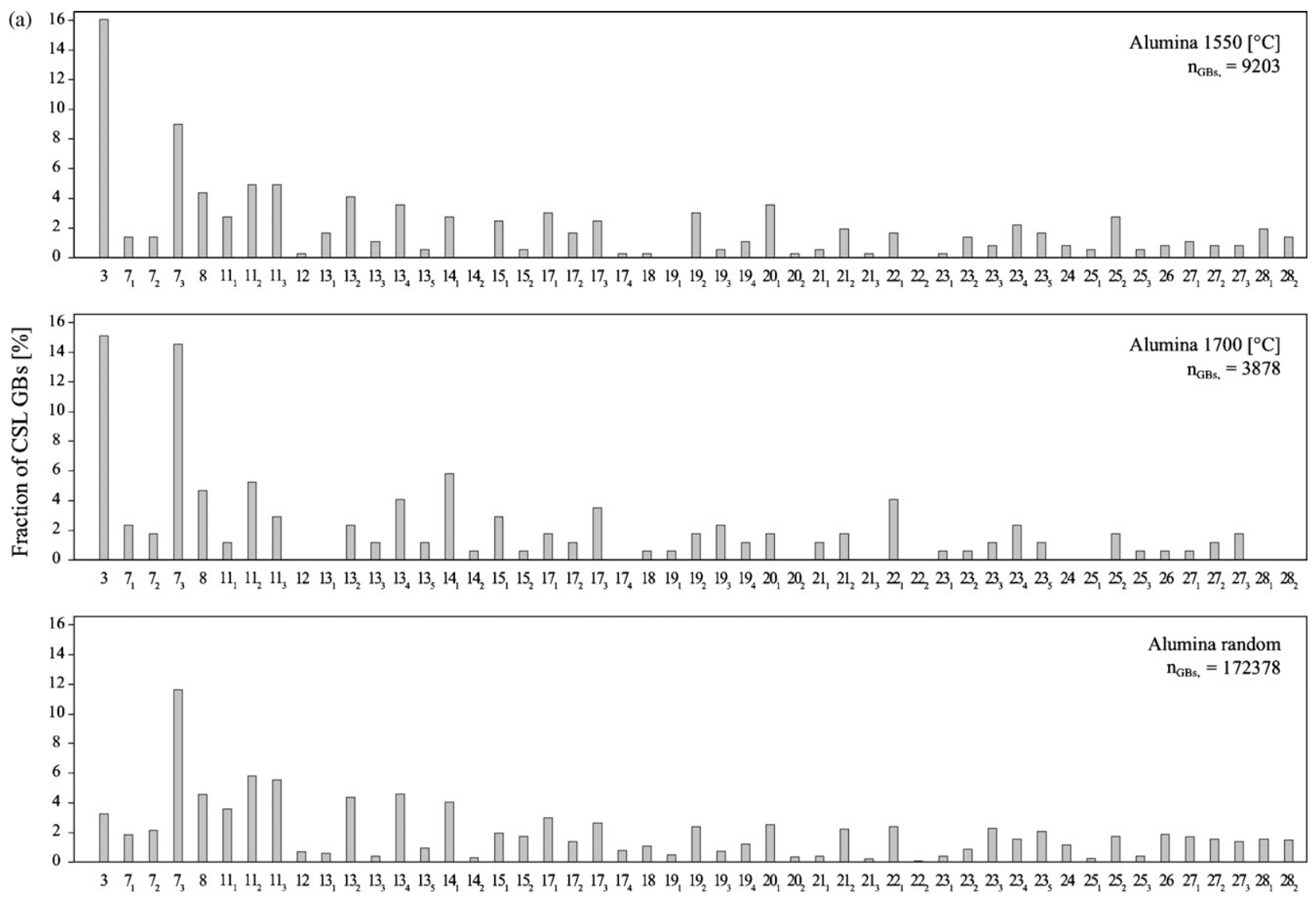

$\Sigma$
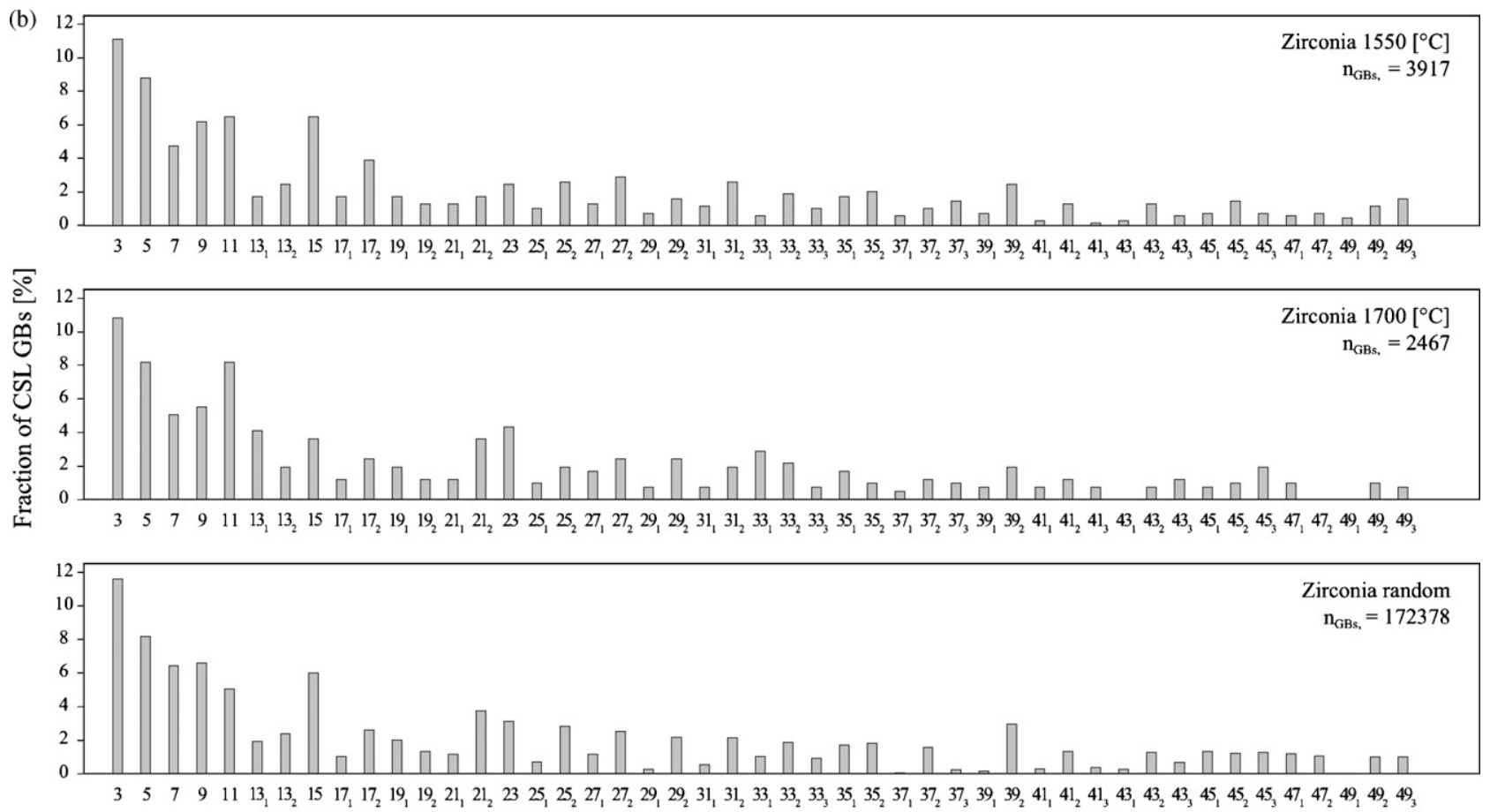

$\Sigma$

Fig. 7. GB character distribution in (a) alumina $(\Sigma 3-\Sigma 28)$ and (b) zirconia $(\Sigma 3-\Sigma 49)$ for the two different sintering temperatures, as well as for the random spatial models; $n_{\mathrm{GBs}}=$ total number of GBs (CSL and non-CSL). 

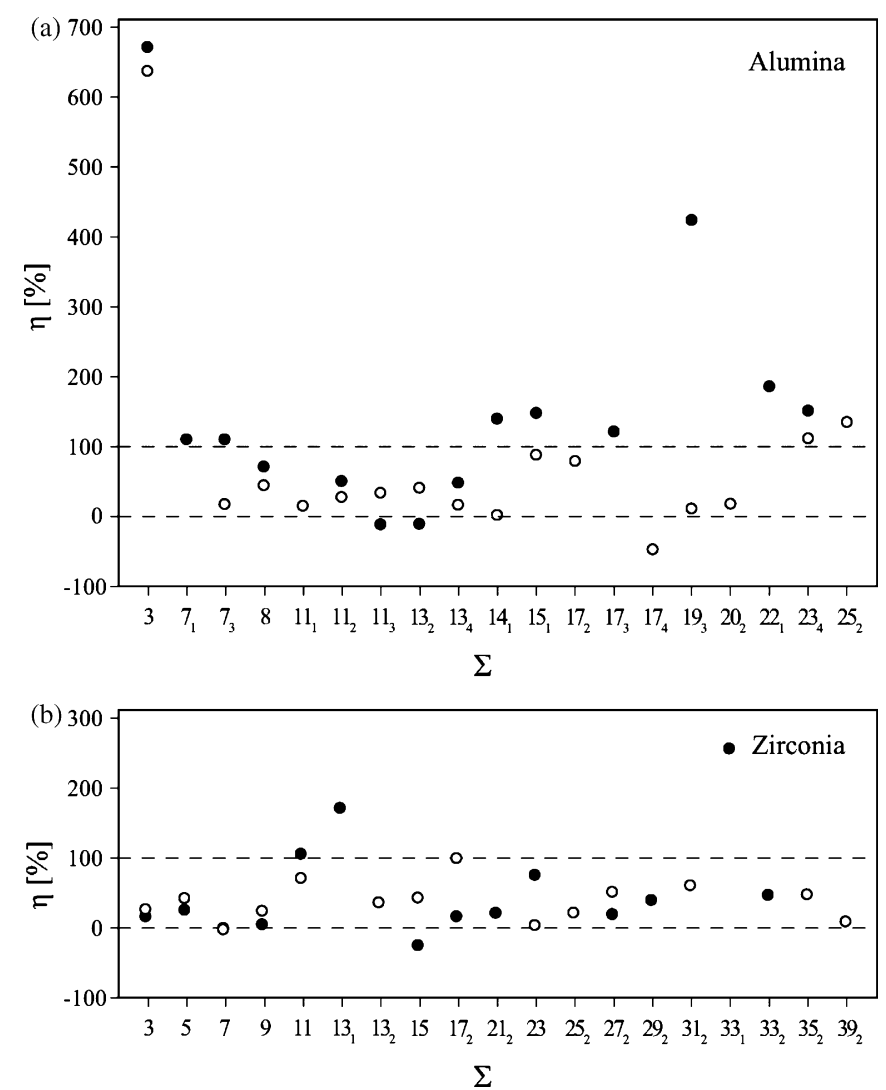

Fig. 8. Relative difference $\eta$ for CSL GBs in (a) alumina and (b) zirconia sintered at $1550{ }^{\circ} \mathrm{C}$ (open circles) and $1700{ }^{\circ} \mathrm{C}$ (full circles). Only the $\Sigma$ values for which $f_{\mathrm{M}} \Sigma>0.1 \%$ is presented. $\eta=0$ indicates that the proportions of CSL GBs in the measured samples and in the models are equal. $\Sigma$ values with $\eta>100 \%$ are mainly observed for high sintering temperature.

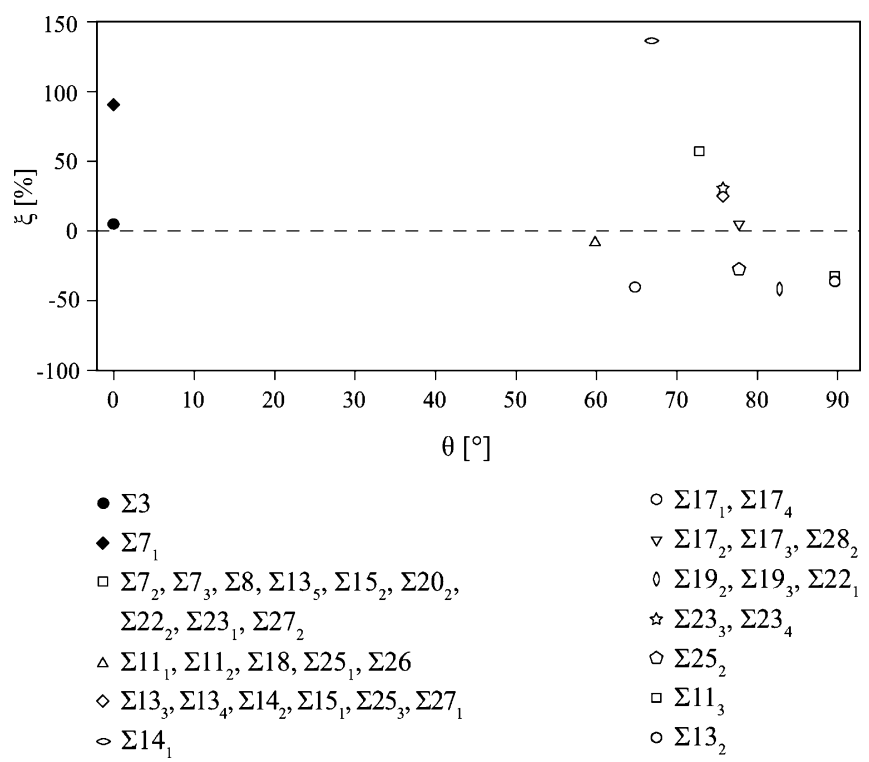

Fig. 9. Plot of the relative difference $\xi$ vs. the angle $\theta$ between $\left[\begin{array}{llll}0 & 0 & 0 & 1\end{array}\right]$ and the CSL misorientation axis in alumina. Only data for which $f_{\mathrm{M}} \Sigma_{1550}$ and/or $f_{\mathrm{M}} \Sigma_{1700}>0.1 \%$ are considered. For the values with the misorientation axis parallel to $\left[\begin{array}{llll}0 & 0 & 0 & 1\end{array}\right]\left(\theta=0^{\circ}\right), f_{\mathrm{M}} \Sigma_{1700}$ is larger than $f_{\mathrm{M}} \Sigma_{1550}$ ( $\xi$ positive), whereas $f_{\mathrm{M}} \Sigma_{1700}$ is smaller than $f_{\mathrm{M}} \Sigma_{1550}$ ( $\xi$ negative) for all values with the misorienta-

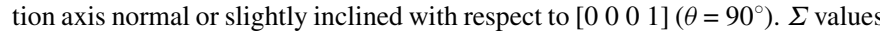
for different $c / a$ with the same misorientation axis and angle plus symmetrically equivalent $\Sigma$ values were added together.

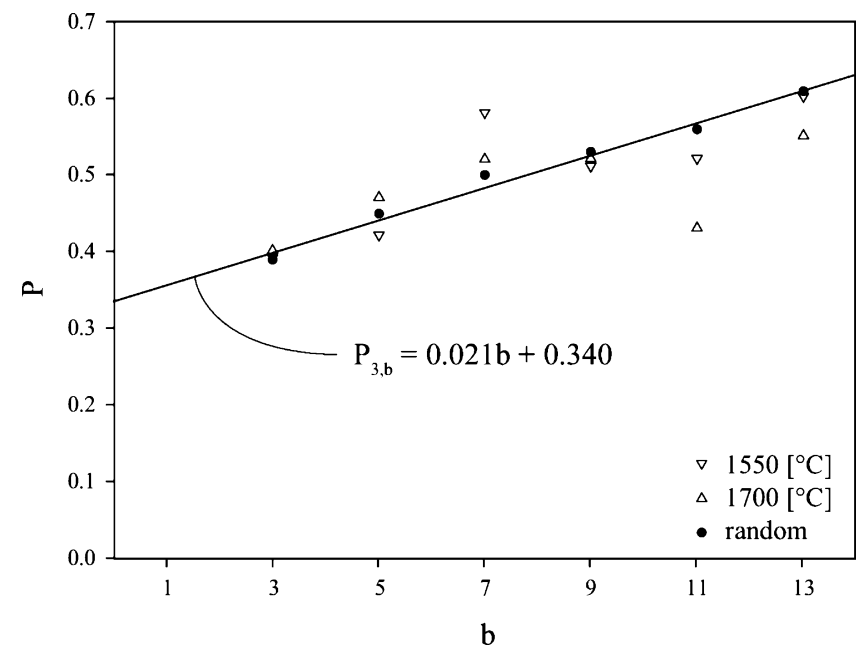

Fig. 10. Linear dependence of the general prominence factor $P$ as a function of parameter $b$ in zirconia.

random CSL GB distribution. For CSL GB triplets related by the function

$\Sigma 3 \Sigma b=\Sigma c$

the following general prominence factor $P$ is linearly dependent on $b$ for values up to $b=13$ :

$P_{3, b}=\frac{f \Sigma 3}{f \Sigma 3+f \Sigma b+f \Sigma c}$

$P_{3, b}=0.021 b+0.340$

The linear dependence resulting from Eq. (10) is a consequence of the symmetry relationships between such triplets. This equation describes over $70 \%$ of the CSL GBs up to $\Sigma 39$. The values of $P_{3, b}$ for both average samples are very close to the theoretical values except $P_{3,7}$ for the samples sintered at $1550{ }^{\circ} \mathrm{C}$ and $P_{3,11}$ for the samples sintered at $1700{ }^{\circ} \mathrm{C}$ (Fig. 10). A more in depth presentation will be given in a forthcoming paper.

\section{Conclusions}

In this paper the grain misorientation and CSL GB distributions in texture-free alumina and zirconia ceramics sintered at two different temperatures were presented and compared with simulated random 2D models. The main points are the following:

(1) The grain misorientation distribution for alumina show relative maxima at $50^{\circ}, 60^{\circ}$, and between $82.5^{\circ}$ and $92.5^{\circ}$ for both sintering temperatures, whereas no relative maxima are observed for zirconia. The maxima and minima in the misorientation distribution are present in all alumina samples independent on the sintering temperature and are most likely due to properties of the starting powders and green body manufacturing processes. This has to be considered when comparing GB character dependencies. 
(2) 2D models for random CSL GB distributions were calculated for microstructures consisting of cubic and trigonal phases. They may serve as reference for the interpretation of EBSD results.

(3) The total number fractions of CSL GBs for both alumina and zirconia are significantly higher in the measurements than in the simulated models.

In alumina, this feature is particularly obvious for $\Sigma 3$, even though most CSL GBs contribute to the trend. Relative difference over $100 \%$ is predominant in the samples sintered at the high temperature. It has been shown that the increase or decrease of the amount of CSL GBs with sintering temperature is crystallographically controlled and dependent on the orientation of the CSL misorientation axis with respect to the [ $\left[\begin{array}{llll}0 & 0 & 0 & 1\end{array}\right]$ axis.

(4) The twin prominence factors $A_{3}$ and $A_{9}$ both for the zirconia average samples and the simulated random model are within the lower and upper bounds defined by Schuh et al. [38] for fcc metals, i.e. 0.5 and 0.9. This suggests that the lower limit of 0.5 might be too small to characterize the twin prominence factors in fcc metals.

(5) A general (non-twin dependent) prominence factor has been proposed for fcc-materials. This parameter shows, for the random case, a linear relationship with $\Sigma$, which could be used as a very simple criterion to determine the randomness of CSL GB distribution in fcc-type materials.

\section{Acknowledgments}

The authors are very grateful to Thomas Graule for his constructive remarks related to our ceramic microstructures, as well as Hans-Jürgen Schindler and Andreas Herzog for the enthusiastic welcome and help in the Hochleistungkeramik laboratory at the EMPA in Dübendorf. We also thank Fiona Gore for reviewing the linguistic aspects of the manuscript. Finally, we appreciate the work of Jean-Paul Bourqui, Patrick Dietsche, Christoph Neururer and René Vonlanthen who lent an extremely valuable technical support during this study.

\section{References}

[1] D. Bernache Assolant, Chimie-Physique du Frittage, Hermès, Paris, 1993.

[2] J. Rodel, A.M. Glaeser, Anisotropy of grains growth in alumina, J. Am. Ceram. Soc. 73 (1990) 3292-3301.

[3] R.M. Cannon, W.H. Rhodes, A.H. Heuer, Plastic deformation of finegrained alumina $\left(\mathrm{Al}_{2} \mathrm{O}_{3}\right)$. 1. Interface-controlled diffusional creep, J. Am. Ceram. Soc. 63 (1980) 46-53.

[4] C. Carry, A. Mocellin, Structural superplasticity in single-phase crystalline ceramics, Ceram. Int. 13 (1987) 89-98.

[5] L. Priester, S. Lartigue, Description and role in the high-temperature deformation of grains boundaries in $\alpha$-alumina ceramics, J. Eur. Ceram. Soc. 8 (1991) 47-57.

[6] W. Swiatnicki, S. Lartigue-Korinek, J.Y. Laval, Grain boundary structure and intergranular segregation in $\mathrm{Al}_{2} \mathrm{O}_{3}$, Acta Metall. Mater. 43 (1995) $795-805$.

[7] J. Cho, C.M. Wang, H.M. Chan, J.M. Rickman, M.P. Harmer, A study of grain-boundary structure in rare-earth doped aluminas using an EBSD technique, J. Mater. Sci. 37 (2002) 59-64.
[8] R.E. Mistler, R.L. Coble, Grain boundary diffusion and boundary widths in metals and ceramics, J. Appl. Phys. 45 (1974) 1507-1509.

[9] W.G. Morris, Physical properties of electrical barriers in varistors, J. Vacuum Sci. Technol. 13 (1976) 926-931.

[10] W.A. Zdaniewski, H.P. Kirchner, Effect of grain boundary oxidation in fracture toughness of SiC, J. Am. Ceram. Soc. 70 (1987) 548-552.

[11] D. Dimos, P. Chaudhari, J. Mannhart, F.K. LeGoues, Orientation dependence of grain boundary critical currents in $\mathrm{YBa}_{2} \mathrm{Cu}_{3} \mathrm{O}_{7}-\delta$ bicrystals, Phys. Rev. Lett. 61 (1988) 219-222.

[12] A.H. King, A. Singh, J.Y. Wang, Principles of grain boundary geometry in noncubic materials, with applications to $\mathrm{YBa}_{2} \mathrm{Cu}_{3} \mathrm{O}_{7}-\delta$, Interf. Sci. 1 (1993) 347-359.

[13] J.Y. Laval, W. Swiatnicki, Atomic structure of grain boundaries in $\mathrm{YBa}_{2} \mathrm{Cu}_{3} \mathrm{O}_{7-\gamma}$, Phys. C 221 (1994) 11-19.

[14] E.F. Wyner, Electrolysis of sodium through alumina arc tubes, J. Illumin. Eng. Soc. 8 (1979) 166-173.

[15] W. Bollmann, Crystal Defects and Crystalline Interfaces, SpringerVerlag, Berlin, 1970.

[16] D.H. Warrington, P. Bufalini, Coincidence site lattice and grain boundaries, Scr. Metall. 5 (1971) 771-776.

[17] S.J. Glass, J.R. Michael, M.J. Readey, S.I. Wright, D.P. Field, Characterization of microstructure and crack propagation in alumina using orientation imaging microscopy (OIM), in: P. Tomsia, A. Glaeser (Eds.), Ceramic Microstructures: Control at the Atomic Level., Plenum Press, New York, 1998, pp. 803-813.

[18] D.I. Kim, F.H. Lee, Y.W. Kim, K.H. Oh, H.C. Lee, EBSD analysis of grain boundary characteristics of abnormally grain grown alumina, Mater. Sci. Forum 408 (2002) 1699-1704.

[19] J. Cho, H.M. Chan, M.P. Harmer, J.M. Rickman, Influence of yttrium doping on grain misorientation in aluminum oxide, J. Am. Ceram. Soc. 81 (1998) 3001-3004.

[20] M. Faryna, J. Jura, K. Sztwiertnia, Orientation imaging microscopy applied to zirconia ceramics, Mikrochim. Acta 132 (2000) 517520.

[21] M. Faryna, E. Bischoff, K. Sztwiertnia, Crystal orientation mapping applied to the Y-TZP/WC composite, Mikrochim. Acta 139 (2002) 5559.

[22] D.J. Prior, A.P. Boyle, F. Brenker, M.C. Cheadle, A. Day, G. Lopez, L. Peruzzo, G.J. Potts, S.M. Reddy, R. Spiess, N.E. Timms, P.W. Trimby, J. Wheeler, L. Zetterström, The application of electron backscatter diffraction and orientation contrast imaging in the SEM to textural problems in rocks, Am. Mineral. 84 (1999) 1741-1759.

[23] P. Stadelmann, A software package for electron-diffraction analysis and HREM image simulation in materials science, Ultramicroscopy 21 (1987) 131-145.

[24] H.J. Bunge, Texture Analysis in Materials Science, Butterworth, London, 1982.

[25] P.H. Pumphrey, K.M. Bowkett, Angle/axis pair description of coincidence site lattice grain boundaries, Scr. Metall. 5 (1971) 365-369.

[26] A. Singh, N. Chandrasekhar, A.H. King, Coincidence orientations of crystals in tetragonal systems, with applications to $\mathrm{YBa}_{2} \mathrm{Cu}_{3} \mathrm{O}_{7-\delta}$, Acta Crystallogr. B 46 (1990) 117-125.

[27] H. Grimmer, Coincidence orientations of grains in rhombohedral materials, Acta Crystallogr. A 45 (1989) 505-523.

[28] D.G. Brandon, Structure of high-angle grain boundaries, Acta Metall. 14 (1966) 1479-1484.

[29] A. Garbacz, M.W. Grabski, The relationship between texture and CSL boundaries distribution in polycrystalline materials. I. The grain-boundary misorientation distribution in random polycrystal, Acta Metallur. Mater. 41 (1993) 469-473.

[30] Y. Pan, B.L. Adams, On the grain boundary distribution in polycrystals, Scr. Metall. Mater. 30 (1994) 1055-1060.

[31] J. Wheeler, D.J. Prior, Z. Ziang, R. Spiess, P.W. Trimby, The petrological significance of misorientations between grains, Contrib. Mineral. Petrol. 141 (2001) 109-124.

[32] G.N. Hassold, E.A. Holm, M.A. Miodownik, Accumulation of coincidence site lattice boundaries during grain growth, Mater. Sci. Technol. 19 (2003) 683-687. 
[33] A. Morawiec, J.A. Szpunar, D.C. Hinz, Texture influence on the frequency of occurrence of CSL-boundaries in polycrystalline materials, Acta Metall. Mater. 41 (1993) 2825-2832.

[34] S. Lartigue, L. Priester, Influence of doping elements on the grain boundary characteristics in alumina, J. Phys. C5-49 (1988) 451-456.

[35] M. Wei, D. Zhi, D.G. Brandon, Microstructure and texture evolution in gel-cast $\alpha$-alumina/alumina platelet ceramic composites, Scr. Mater. 53 (2005) 1327-1332.

[36] C. Scott, M. Kaliszewski, C. Greskovich, L. Levinson, Conversion of polycrystalline $\mathrm{Al}_{2} \mathrm{O}_{3}$ into single-crystal sapphire by abnormal grain growth, J. Am. Ceram. Soc. 85 (2002) 1275-1280.
[37] R.W. Minich, C.A. Schuh, M. Kumar, Role of topological constraints on the statistical properties of grain boundary networks, Phys. Rev. B 66 (2002) 052101.

[38] C.A. Schuh, M. Kumar, W.E. King, Universal features of grain boundary networks in fcc materials, J. Mater. Sci. 40 (2005) 847-852.

[39] V.Y. Gertsman, K. Tangri, Computer-simulation study of grain-boundary and triple junction distributions in microstructures formed by multiple twinning, Acta Metall. Mater. 43 (1995) 2317-2324.

[40] G. Palumbo, K.T. Aust, U. Erb, P.J. King, A.M. Brennenstuhl, P.C. Lichtenberger, On annealing twins and CSL distributions in fcc polycrystals, Phys. Status Solidi A 131 (1992) 425-428. 